\title{
Reexamining the causality of causal attributions in depression: A failure to replicate
}

\author{
CHARLES S. CARVER and LAWRENCE LA VOIE \\ University of Miami, Coral Gables, Florida
}

\begin{abstract}
In 1981, Golin, Sweeney, and Shaeffer found an association between attributional style and subsequent depression, using a cross-lag panel design. This finding is widely viewed as showing that attributional tendencies exert a unidirectional causal influence on the development of depressed affect. This article reports a failure to obtain a comparable result from a very similar study.
\end{abstract}

Recent attempts to understand the bases of exogenous depression have been guided in part by an attributionbased version of helplessness theory (see, e.g., Abramson, Seligman, \& Teasdale, 1978; Weiner \& LitmanAdizes, 1980). The logic behind this theory is that attributional dimensions mediate the development of perceptions of noncontingency between behavior and outcome, and thus mediate the development of depression. This reasoning suggests that certain kinds of attributional styles may predispose people to become depressed.

In order to investigate possibilities such as this, an Attributional Style Questionnaire (ASQ) was developed (Seligman, Abramson, Semmel, \& von Baeyer, 1979). It presents respondents with a series of positive and negative hypothetical events that they are to imagine happening to them. Respondents record the single most important causal influence in the event, and then make a series of ratings of the cause, in terms of its internality, stability, and globality. In scoring, these ratings are summed across events, within each causal dimension, and within event type.

A number of researchers have obtained reliable correlations between depression and the attributional dimensions as assessed by the ASQ. Of perhaps greater interest, at least one research project has found that ASQ scores predicted depression prospectively in a cross-lag panel design (Golin, Sweeney, \& Shaeffer, 1981). More concretely, this study found that three individual dimensions of the ASQ exhibited the following pattern of relations with depression (as assessed by the BDI, Beck, 1967): In each case, ASQ scores collected at Time 1 correlated with BDI scores collected at Time 2, but the correlation of BDI at Time 1 with ASQ at Time 2 was near zero. This pattern is often viewed as suggestive of a causal influence of one variable (in this case, the ASQ) on the other (the BDI). (See Golin et al., 1981, or Kenny, 1975, for a more complete description of the rationale behind the use of

Please address correspondence to: C. S. Carver, Department of Psychology, University of Miami, P. O. Box 248185, Coral Gables, FL 33124. the panel design in making a case for causal influence.) These data thus appear to provide evidence of the causal role of attributional style in creating a susceptibility to depression.

This article reports additional data bearing on this issue, which appear to call into question the reliability of the Golin et al. (1981) findings.

\section{METHOD}

Subjects in this study were 167 undergraduates who completed the self-report measures in each of two large group sessions. Session 1 was near the beginning of an academic semester. Session 2 , which was not mentioned at the initial testing, took place exactly 6 weeks later. In each session, subjects completed the ASQ and the short form of the BDI (the same version that was used by Golin et al., 1981), along with additional measures. Instructions delivered verbally at Session 2 acknowledged that some of the subjects may have seen some of the instruments before, but requested that subjects respond to all items as if they had never seen them.

\section{RESULTS}

Table 1 displays the means of the six ASQ scales, as obtained at the two sessions, along with the correlations between each scale and BDI. To the right of these figures, for comparison purposes, are the correlations reported by Golin et al. (1981). It should be obvious from these figures that there is substantial similarity in the patterns of relationships emerging from the two studies at any given measurement period, although there are also slight differences (none of which was significant, however, by $Z$ test). Of greatest relevance to present concerns are the significant correlations between BDI and each measure of badoutcome attribution, at each point of measurement, in each sample. The relationships for the good-outcome scales are more erratic both within each sample and across samples. (As was true of the Golin et al. (1981) data, analyses in which BDI scores were subjected to log transformations yielded a pattern that was essentially identical to the values reported here.)

The test-retest correlations obtained from the present sample were quite comparable to those reported by Golin et al. (1981), even though the present sample had a 6- 
Table 1

Means of ASQ Scales and Correlations with BDI

\begin{tabular}{|c|c|c|c|c|}
\hline & & Mean & $r$ with BDI & $\begin{array}{c}r \text { with BDI } \\
\text { (Golin et al., 1981) }\end{array}$ \\
\hline \multicolumn{5}{|c|}{ Bad-Outcome Scales } \\
\hline Internal & $\begin{array}{l}1 \\
2\end{array}$ & $\begin{array}{l}24.01 \\
24.60\end{array}$ & $\begin{array}{l}.20 \dagger \\
.19 \dagger\end{array}$ & $\begin{array}{l}.10^{*} \\
.18 \dagger\end{array}$ \\
\hline Stable & $\begin{array}{l}1 \\
2\end{array}$ & $\begin{array}{l}22.95 \\
23.59\end{array}$ & $\begin{array}{l}.16^{*} \\
.17^{*}\end{array}$ & $\begin{array}{l}.20 \dagger \\
.23 \dagger\end{array}$ \\
\hline Global & $\begin{array}{l}1 \\
2\end{array}$ & $\begin{array}{l}21.77 \\
23.10\end{array}$ & $\begin{array}{l}.27 \dagger \\
.19 \dagger\end{array}$ & $\begin{array}{l}.11^{*} \\
.16^{*}\end{array}$ \\
\hline Internal & $\begin{array}{l}1 \\
2\end{array}$ & $\begin{array}{l}32.78 \\
32.66\end{array}$ & $\begin{array}{c}\text { Outcome Sca } \\
-.18^{*} \\
.05\end{array}$ & $\begin{array}{l}-.17 \dagger \\
-.22 \dagger\end{array}$ \\
\hline Stable & $\begin{array}{l}1 \\
2\end{array}$ & $\begin{array}{l}33.40 \\
33.23\end{array}$ & $\begin{array}{l}-.12 \\
-.14\end{array}$ & $\begin{array}{l}-.05 \\
-.16^{*}\end{array}$ \\
\hline Global & $\begin{array}{l}1 \\
2\end{array}$ & $\begin{array}{l}31.86 \\
32.45\end{array}$ & $\begin{array}{l}-.21 \dagger \\
-.08\end{array}$ & $\begin{array}{r}.02 \\
-.13 \\
\end{array}$ \\
\hline
\end{tabular}

Note-The column on the right shows the comparable relationships reported by Golin et al. (1981). BDI Mean $=2.53, S D=3.32$, and Mean $=2.31, S D=3.27$, respectively, for the two sessions. ${ }^{*} p<.05$; $\dagger p<.01$.

Table 2

Cross-Lag Correlations between ASQ and BDI Scores

\begin{tabular}{|c|c|c|c|c|}
\hline & \multicolumn{2}{|c|}{ Present Study } & \multicolumn{2}{|c|}{ Golin et al. (1981) } \\
\hline & ASQ to BDI & BDI to ASQ & ASQ to BDI & BDI to ASQ \\
\hline \multicolumn{5}{|c|}{ Bad-Outcome Scales } \\
\hline Internal & .14 & .15 & .11 & .13 \\
\hline Stable & .14 & .14 & .32 & .09 \\
\hline Global & .19 & .21 & .18 & .01 \\
\hline \multicolumn{5}{|c|}{ Good-Outcome Scales } \\
\hline Internal & -.07 & -.04 & -.20 & -.17 \\
\hline Stable & -.07 & -.15 & -.16 & .02 \\
\hline Global & -.11 & -.08 & .01 & -.06 \\
\hline
\end{tabular}

*Signifies that the differences between pairs of cross-lags was significant in the Golin et al. data.

week interval between sessions, whereas the previous sample had only a 4-week interval. The retest correlations for the present sample were as follows (with those reported by Golin et al. in parentheses): for BDI, $r=.62(.57)$; for ASQ good outcomes, internality $r=.50(.66)$, stability $r=.50(.56)$, globality $r=.55(.51)$; for ASQ bad outcomes, internality $r=.50(.47)$, stability $r=.64(.61)$, and globality $r=.63(.65)$.

Meaningful examination of cross-lags relies on the assumption of stationarity of correlations between relevant variables across time (see Rogosa, 1980). A test of this assumption, using the maximum likelihood procedure recommended by Kenny and Harackiewicz (1979), yielded a nonsignificant chi-square $\left[\chi^{2}(6)=12.33\right.$, $p>.05]$, thus supporting a model of perfect stationarity (all analyses reported here used LISREL V, Jöreskog \& Sörbom, 1981). The equivalence of the autocorrelations, although not an assumption of the cross-lag procedure, was also tested by assessing the change in chi-square from a model assuming only perfect stationarity to a model with the additional constraint of equal autocorrelations. Again, the difference was not significant $\left[\chi^{2}(6)=8.58\right.$, $p>.05$ ], supporting the assumption of equivalent autocorrelations. These analyses indicate the appropriateness of examining the cross-lag correlations.

Table 2 displays the cross-lags from the present sample, along with those reported by Golin et al. (1981). The first column in each set is the association of ASQ at Time 1 with BDI at Time 2; the second column is the association of BDI at Time 1 with ASQ at Time 2 . As is apparent from the figures on the left side of Table 2, our data revealed absolutely no indication of temporal precedence of attributions with respect to depression. This was confirmed by a test of spuriousness, or of the difference between cross-lags, under the assumption of perfect stationarity $\left[\chi^{2}(6)<1.0\right]$.

\section{DISCUSSION}

The data of the present sample displayed a pattern of interrelationships that was intelligible and, indeed, was similar to the pattern obtained by Golin et al. (1981) in every respect save one: specifically, the cross-lag correlations obtained here did not suggest a unidirectional causal influence of attributions on depression. The two studies differed from each other in three minor ways, but none suggests any obvious basis for the difference in results. Subjects in both cases were (largely nondepressed) college students, but they came from different universities. Golin et al. used a 4-week interval between testings; the interval here was 6 weeks. Finally, Golin et al. counterbalanced the order of the questionnaires; we did not. Are these differences important? The fact that the pattern of relationships at each session was quite comparable between the two studies suggests that the answer is no.

It is always difficult to know exactly what to make of a failure to replicate. The standard response to divergent results is to suggest the need for additional evidence. In this case, the natural reluctance to conduct simple replications is compounded by the fact that panel studies are relatively expensive, in terms of the effort needed to collect and analyze the data. Nevertheless, the data presented here appear to urge caution in accepting the earlier finding as reliable.

We should note that this failure to replicate is amenable to a second interpretation. Specifically, rather than questioning the causal role of attributions in depression, the failure may be seen as casting doubt on the usefulness of the cross-lag panel design in addressing the issue (see Rogosa, 1980). Several other researchers have investigated the possible causal influence of attributional style on depression using designs other than the panel design used here. Usually, but not always, these researchers assess subjects' attributional style prior to some stressful event, and then examine patterns of change in depression in response to the stressor. Some of these studies have obtained support for the position that attributional style is a risk factor for depression (e.g., Cutrona, 1983; Metalsky, Abramson, Seligman, Semmel, \& Peterson, 1982; O'Hara, Rehm, \& Campbell, 1982); others have not (e.g., Hamilton \& Abramson, 1983; Manly, McMahon, Bradley, \& Davidson, 1982; see also Coyne \& Gotlib, 1983, for criticism of this line of research on other grounds). The majority of these studies, however, focused on a period in which some distinct stressor or aversive event would inevitably occur in the lives of at least some of the subjects. The present findings may be interpreted as indicating the critical importance of ensuring the occurrence of such events during the period under study, rather than simply assuming that they will occur, a point that also has been made by Metalsky et al. (1982).

\section{REFERENCES}

Abramson, L. Y., Seligman, M. E. P., \& Teasdale, J. D. (1978). Learned helplessness in humans: Critique and reformulation. Journal of Abnormal Psychology, 87, 49-74.

BECK, A. T. (1967). Depression: Clinical, experimental, and theoretical aspects. New York: Harper \& Row. 
Coyne, J. C., \& Gotulb, I. H. (1983). The role of cognition in depression: A critical appraisal. Psychological Bulletin, 94, 472-505.

Cutrona, C. E. (1983). Causal attributions and perinatal depression. Journal of Abnormal Psychology, 92, 161-172.

Golin, S., Sweeney, P. O., \& ShaefFer, D. F. (1981). The causality of causal attributions: A cross-lagged panel correlational analysis. Journal of Abnormal Psychology, 90, 14-22.

Hamilton, E. W., \& Abramson, L. Y. (1983). Cognitive patterns and major depressive disorder: A longitudinal study in a hospital setting. Journal of Abnormal Psychology, 92, 173-184.

JöRESKOG, K. G., \& SöRBOM, D. (1981). LISREL V: Analysis of linear structural relationships by maximum likelihood and least squares methods. Chicago, IL: International Educational Services.

KenNy, D. A. (1975). Cross-lagged panel correlation: A test for spuriousness. Psychological Bulletin, 82, 887-903.

KenNy, D. A., \& HaRACKIEWICZ, J. M. (1979). Cross-lagged panel correlation: Practice and promise. Journal of Applied Psychology, 64, 372-379.

Manley, P. C., McMahon, R. J., Bradley, C. F., \& Davidson, P. O. (1982). Depressive attributional style and depression following childbirth. Journal of Abnormal Psychology, 91, 245-254.
Metalsky, G. I., Abramson, L. Y., Seligman, M. E. P., SemMEL, A., \& Peterson, C. (1982). Attributional styles and life events in the classroom: Vulnerability and invulnerability to depressive mood reactions. Journal of Personality \& Social Psychology, 43, 612-617.

O'Hara, M. W., Rehm, L. P., \& Campbell, S. B. (1982). Predicting depressive symptomatology: Cognitive-behavioral models and postpartum depression. Journal of Abnormal Psychology, 91, 457-461. Rogosa, D. (1980). A critique of cross-lagged correlation. Psychological Bulletin, 88, 245-258.

Seligman, M. E. P., Abramson, L. Y., Semmel, A., \& von Baeyer, C. (1979). Depressive attributional styles. Journal of Abnormal Psychology, 88, 242-247.

Weiner, B., \& LiTMan-Adizes, T. (1980). An attributional, expectancyvalue analysis of learned helplessness and depression. In J. Garber \& M. E. P. Seligman (Eds.), Human helplessness: Theory and applications. New York: Academic Press.

(Manuscript received for publication December 9, 1985.) 